\title{
Anti-TNF-a treatment modulates SASP and SASP-related microRNAs in endothelial cells and in circulating angiogenic cells
}

\author{
Francesco Prattichizzo ${ }^{1,2}$, Angelica Giuliani ${ }^{1}$, Rina Recchioni ${ }^{3}$, Massimiliano \\ Bonafè $^{4}$ Fiorella Marcheselli3 ${ }^{3}$ Sabrina De Carolis ${ }^{4}$, Anna Campanati ${ }^{5}$ Katia \\ Giuliodori $^{5}$, Maria Rita Rippo ${ }^{1}$, Francesca Brugè ${ }^{6}$, Luca Tiano ${ }^{6}$, Carla Micucci ${ }^{1}$, \\ Antonio Ceriello², Annamaria Offidani ${ }^{5}$, Antonio Domenico Procopio ${ }^{1,3}$ and Fabiola \\ Olivieri ${ }^{1,3}$ \\ ${ }^{1}$ Department of Clinical and Molecular Sciences, DISCLIMO, Università Politecnica delle Marche, Ancona, Italy \\ ${ }^{2}$ Insititut d'Investigacions Biomèdiques August Pi i Sunyer (IDIBAPS) and Centro de Investigación Biomédica en Red de \\ Diabetes y Enfermedades Metabólicas Asociadas (CIBERDEM), Barcelona, Spain and IRCCS MultiMedica Sesto San Giovanni \\ (MI), Italy \\ ${ }^{3}$ Center of Clinical Pathology and Innovative Therapy, National Institute INRCA-IRCCS, Ancona, Italy \\ ${ }^{4}$ Department of Experimental, Diagnostic and Specialty Medicine, DIMES, University of Bologna, Bologna, Italy \\ ${ }^{5}$ Dermatology Clinic, Department of Clinical and Molecular Medicine, Università Politecnica delle Marche, Ancona, Italy \\ ${ }^{6}$ Department of Clinical and Dental Sciences, DISCO, Università Politecnica delle Marche, Ancona, Italy \\ Correspondence to: Anna Campanati, email: anna.campanati@gmail.com \\ Keywords: miR-146a-5p, miR-126-3p, SASP, HUVEC, replicative senescence, Gerotarget \\ Received: December 04, 2015 Accepted: February 14, $2016 \quad$ Published: March 02, 2016
}

\section{ABSTRACT}

Endothelial cell senescence is characterized by acquisition of senescenceassociated secretory phenotype (SASP), able to promote inflammaging and cancer progression. Emerging evidence suggest that preventing SASP development could help to slow the rate of aging and the progression of age-related diseases, including cancer. Aim of this study was to evaluate whether and how adalimumab, a monoclonal antibody directed against tumor necrosis factor-a (TNF-a), a major SASP component, can prevent the SASP. A three-pronged approach has been adopted to assess the if adalimumab is able to: $i)$ modulate a panel of classic and novel senescence- and SASP-associated markers (interleukin [IL]-6, senescence associated- $\beta$-galactosidase, p16/Ink4a, plasminogen activator inhibitor 1, endothelial nitric oxide synthase, miR-146a-5p/Irak1 and miR-126-3p/Spred1) in human umbilical vein endothelial cells (HUVECs); ii) reduce the paracrine effects of senescent HUVECs' secretome on MCF-7 breast cancer cells, through wound healing and mammosphere assay; and iii) exert significant decrease of $\mathrm{miR-146a-5p}$ and increase of $\mathrm{miR-126-3p}$ in circulating angiogenic cells (CACs) from psoriasis patients receiving adalimumab in monotherapy.

TNF-a blockade associated with adalimumab induced significant reduction in released IL-6 and significant increase in eNOS and miR-126-3p expression levels in long-term HUVEC cultures.

A significant reduction in miR-146a-5p expression levels both in long-term HUVEC cultures and in CACs isolated from psoriasis patients was also evident. Interestingly, conditioned medium from senescent HUVECs treated with adalimumab was less consistent than medium from untreated cells in inducing migration- and mammosphere- promoting effects on MCF-7 cells.

Our findings suggest that adalimumab can induce epigenetic modifications in cells undergoing senescence, thus contributing to the attenuation of SASP tumorpromoting effects. 


\section{INTRODUCTION}

The senescence status of stromal cells, including endothelial cells (ECs), plays a major role in inflammaging [1], the low-grade, chronic, and systemic inflammatory condition associated to aging [2]. Cellular senescence is related to the acquisition of a discrete phenotype, the so called senescence-associated secretory phenotype (SASP), characterized by the activation of a pro-inflammatory transcriptional program [3-6]. Accordingly, the pathways involved in SASP acquisition, as the NF-kB and the IL-1/ NLRP3 inflammasome pathways are master modulators of the aging rate [7-12]. Notably, removal of senescent cells in animal models, is able to prolong lifespan and healthspan [13]. Evidence that the number of senescent dermal fibroblasts correlates with the presence of some age-related diseases (ARDs) has also been reported in humans [14].

Interventions directed at preventing the adverse effects associated with the SASP are being explored The most promising strategies involve delaying cellular senescence [15, 16]; SASP switch-off [17-20]; and selective removal or killing of existing senescent cells [1, 21]. Even though SASP involves the release of hundreds of molecules [3, 4], like interleukin (IL)-1, IL-6, IL-8, tumor growth factor (TGF)- $\beta$, and tumor necrosis factor (TNF)- $\alpha$, the most common and best characterized [4, 2226]. Some of these cytokines can induce or reinforce the senescent phenotype by acting in autocrine and paracrine manner, spreading senescence via a "bystander effect" $[9,22,26]$. However, TNF- $\alpha$ inhibition in relation to EC senescence and SASP acquisition has not been already extensively explored yet. TNF- $\alpha$ can promote senescence in endothelial progenitor cells [27] and human umbilical vein endothelial cell (HUVEC) cultures [28], and it has well-known adverse effects on endothelial function in vivo [29-31]. However the molecular basis for these effects has not been fully elucidated yet.

Here we tested whether TNF- $\alpha$ blockade can reduce the acquisition of the senescent phenotype and/or the SASP by HUVECs, an in vitro EC model. TNF- $\alpha$ was inhibited by administration of adalimumab, a monoclonal antibody directed against TNF- $\alpha$ that has been licensed for use in psoriasis [30-34]. To gain insights into the ability of anti-TNF- $\alpha$ treatment to induce epigenetic modifications in vivo, microRNAs (miRNAs), key modulators of gene expression, were analyzed in circulating angiogenic cells (CACs) from psoriasis patients treated with adalimumab.

The ability of adalimumab to restrain or delay SASP acquisition was tested by evaluating two senescence/ SASP-associated miRNAs (miR-126-3p and miR-146a$5 \mathrm{p})$ and the respective targets (Spred1 and Irak1) [35] as well as a panel of classic senescence- and SASPassociated markers: senescence associated- $\beta$-galactosidase (SA- $\beta$-Gal) [36], p16/Ink4a [37], plasminogen activator inhibitor 1 (PAI1) [38], endothelial nitric oxide synthase
(eNOS) [39] and the prototypical SASP protein IL-6 [3].

Moreover, since the inflammatory tumor microenvironment plays a pivotal role in cancer promotion and progression, and SASP could contribute to tumor growth and tumor cell motility and invasiveness [3, 4, 17], this study also investigates whether anti-TNF- $\alpha$ treatment can modulate the effect of the secretome of senescent ECs on tumor cell motility and on its ability to promote mammosphere formation.

\section{RESULTS}

\section{Anti-TNF- $\alpha$ treatment of THP-1 cells}

Since activated monocytes are major TNF- $\alpha$ producers, and adalimumab is a specific antibody inhibiting its autocrine and paracrine proinflammatory effects, we first tested its ability to modulate miR-146a$5 \mathrm{p}$ (an inflamma-miR), miR-126-3p (an endo-miR), and Spred1 and Irak1 (two of their targets) in the human monocytic cell line THP-1 exposed to LPS stimulation for $30 \mathrm{~min}$ or $5 \mathrm{~h}$. The levels of the two miRs and the amount of target proteins determined in cells not exposed to LPS were considered as baseline. LPS stimulation induced a significantly increased release of TNF- $\alpha$ that was highest at $5 \mathrm{~h}$, it raised miR-146a-5p expression, and reduced miR126a-3p levels (Figure 1A, 1B, and 1C). Irak1 protein rose significantly at $30 \mathrm{~min}$ whereas Spred 1 levels peaked at 5 $\mathrm{h}$, but the latter change was modest (Figure 1D).

Interestingly, pretreatment with anti-TNF- $\alpha$ for 24 $\mathrm{h}$ significantly inhibited LPS-induced miR-146a-5p upregulation and miR-126-3p down-regulation (Figure 1B and $1 \mathrm{C}$ ), it attenuated the increase in Irak1 levels (Figure 1D), and completely abolished the slight increase in Spred1 protein (Figure 1D).

\section{Anti-TNF- $\alpha$ treatment of HUVECs}

\section{1) Effects of TNF- $\alpha$ inhibition on young and senescent HUVECs}

\section{- Modulation of miR-146a/Irak1 and miR-126-3p/ Spred1}

Also in the case of HUVECs, LPS stimulation induced release of an increased amount of TNF- $\alpha$ that was highest at $5 \mathrm{~h}$ (Figure 2A). Since HUVECs undergoing replicative senescence in vitro acquire the SASP, i.e. the pro-inflammatory secretory phenotype characterized by increased release of TNF- $\alpha$ and others cytokines (Figure 2A) [15], the inhibitory effect of TNF- $\alpha$ on LPS-treated HUVECs was assayed separately in young and senescent 
cells. The latter were identified based on the expression of senescence-associated biomarkers, including SASP acquisition (SA- $\beta-\mathrm{Gal}>50 \%)$.

The anti-TNF- $\alpha$ concentration used in our experiments $(8 \mu \mathrm{g} / \mathrm{ml})$, similar to the level measured in the blood of patients treated with adalimumab [40], affected neither the proliferation of young HUVECs (Supplementary Figure 1A) nor the metabolic activity of both young and senescent HUVECs as evaluated by the MTT assay (Supplementary Figure 1B), suggesting that adalimumab does not exert an effective senolytic activity.

MiR-146a-5p and miR-126-3p levels were higher in senescent than in young HUVECs (Figure 2A and 2D). However, while LPS exposure raised miR-146a-5p levels in both sets of cells, miR-126-3p was significantly down- regulated in senescent cells at $5 \mathrm{~h}$, whereas in young cells it was not significantly affected either by LPS or by antiTNF- $\alpha$ (Figure 2B and 2E), in line with earlier reports [39, 41].

Comparison of miR-146a-5p expression in young and senescent cells after $24 \mathrm{~h}$ adalimumab pretreatment highlighted a significant inhibitory effect only in senescent cells, both before and after $5 \mathrm{~h}$ LPS exposure (Figure 2B and $2 \mathrm{C}$ ). Similar results were obtained with different doses of adalimumab (Supplementary Figure 1C).

Irak1 protein levels paralleled the trend of miR146a-5p expression (Figure 2F).

As regards Spred1, its expression was significantly reduced in senescent cells treated with adalimumab and exposed to LPS (Figure 2F), closely paralleling miR-126-

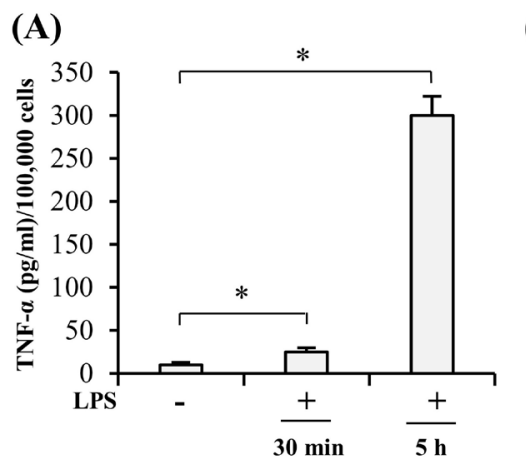

(D)

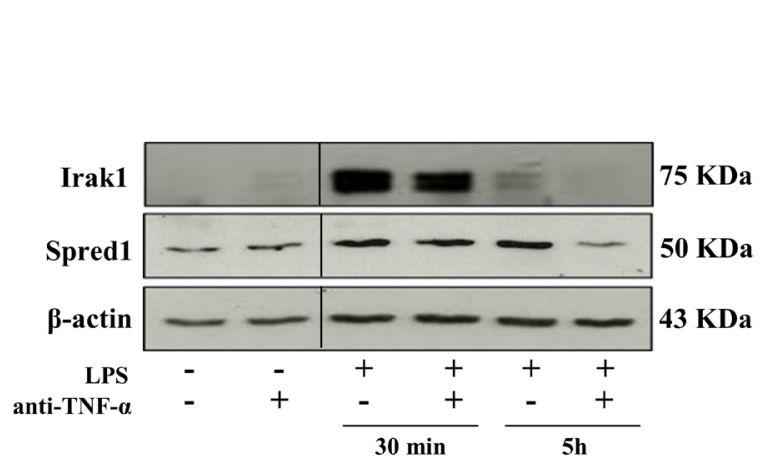

(B)

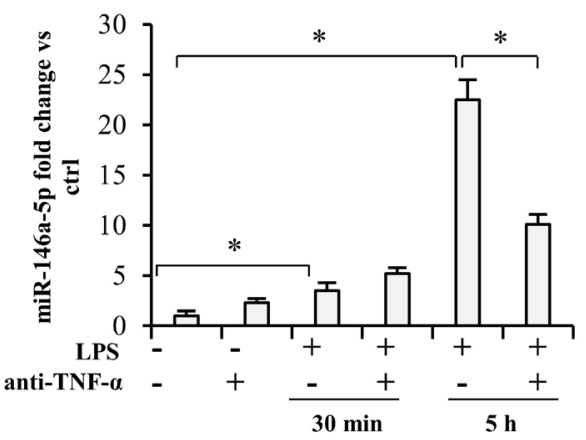

(C)

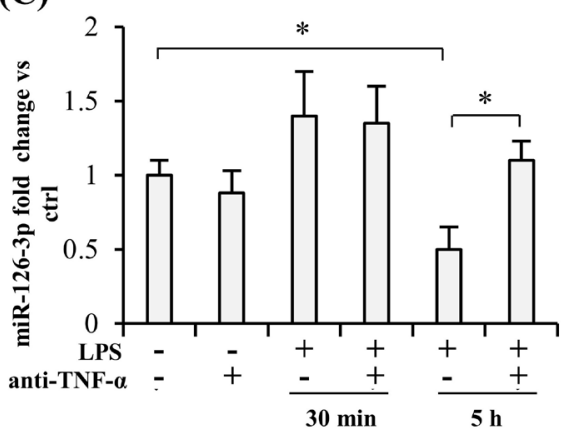

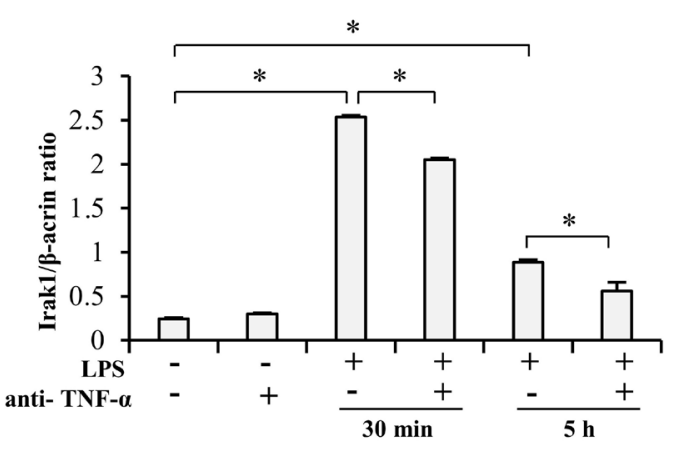

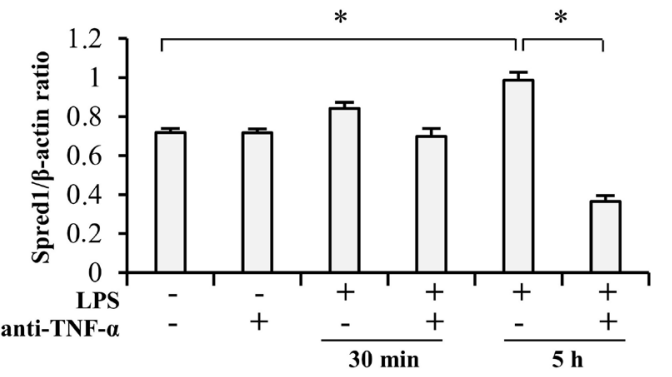

Figure 1: Effect of TNF- $\alpha$ blockade on the expression of miRs and their target proteins in LPS-exposed THP-1 cells. A. TNF- $\alpha$ release into the culture medium by THP- 1 cells after LPS treatment $(1 \mu \mathrm{g} / \mathrm{ml})$, expressed as pg/ml per 100,000 cells. B. MiR146a-5p expression in THP-1 cells after 30 min or $5 \mathrm{~h}$ (hours) LPS exposure, with/without $24 \mathrm{~h}$ anti-TNF- $\alpha$ pretreatment, measured as fold change $v s$ ctrl. C. MiR-126-3p expression in THP-1 cells after $30 \mathrm{~min}$ or $5 \mathrm{~h}$ LPS exposure, with/without $24 \mathrm{~h}$ anti-TNF- $\alpha$ pretreatment, measured as fold change $v s$ ctrl. D. Irak1 and Spred1 expression levels and densitometry data in THP-1 cells after 30 min or 5 h LPS stimulation, with/without $24 \mathrm{~h}$ anti-TNF- $\alpha$ pretreatment. * Student's $t$ test, $p<0.05$. Data are mean \pm S.D. of 3 independent experiments. 
(A)

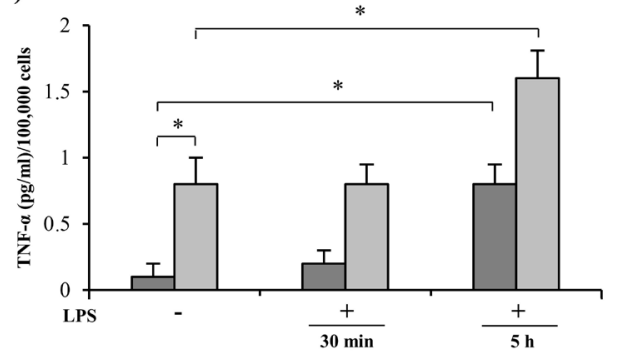

(B)

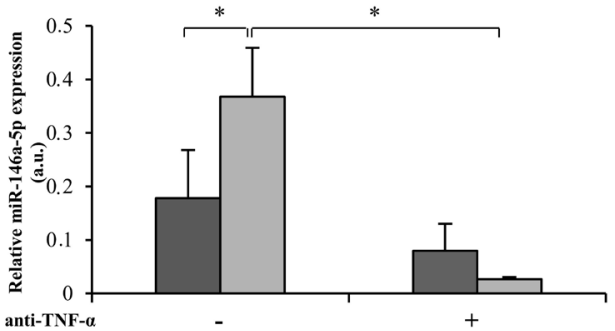

(D)

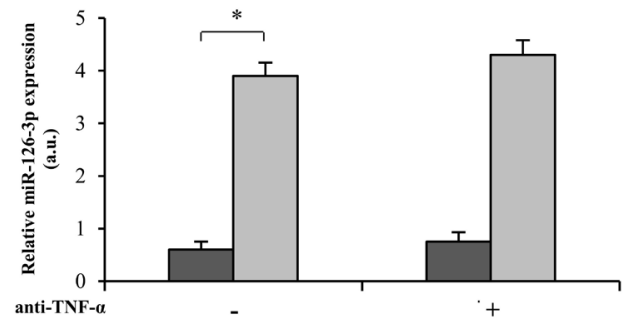

(F)

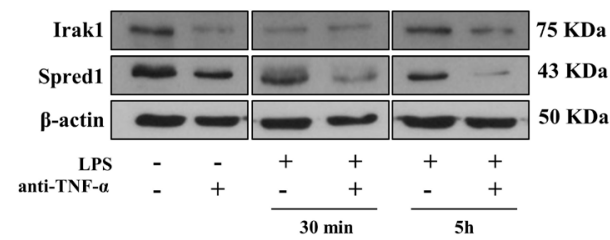

Figure 2: Effect of TNF- $\alpha$ blockade on the expression of miRs and their target proteins in senescent (SA- $\beta$-Gal $>50$ $\%)$ and young (SA- $\beta-G a l<5 \%)$ HUVECs with and without LPS-stimulation. A. TNF- $\alpha$ release into the culture medium by LPS-exposed $(1 \mu \mathrm{g} / \mathrm{ml})$ young and senescent HUVECs, expressed as pg/ml per 100,000 cells. B. MiR-146a-5p expression in young and senescent HUVECs with/without $24 \mathrm{~h}$ anti-TNF- $\alpha$ pretreatment, measured as relative expression (a.u). C. MiR-146a-5p expression in young and senescent HUVECs after $30 \mathrm{~min}$ or $5 \mathrm{~h}$ LPS stimulation, with/without $24 \mathrm{~h}$ anti-TNF- $\alpha$ pretreatment, measured as fold change vs ctrl. D. MiR-126-3p expression in young and senescent HUVECs with/without $24 \mathrm{~h}$ anti-TNF- $\alpha$ pretreatment, measured as relative expression (a.u). E. MiR-126-3p expression in young and senescent HUVECs after $30 \mathrm{~min}$ or $5 \mathrm{~h}$ LPS stimulation, with/without $24 \mathrm{~h}$ anti-TNF- $\alpha$ pretreatment, measured as fold change $v s$ ctrl. F. Irak1 and Spred1 expression and densitometry data in young and senescent HUVECs after $30 \mathrm{~min}$ or $5 \mathrm{~h}$ LPS stimulation, with/without $24 \mathrm{~h}$ anti-TNF- $\alpha$ pretreatment. * Student's $t$ test, $p<0.05$. Data are mean \pm S.D. of 3 independent experiments.
(C)

(E)
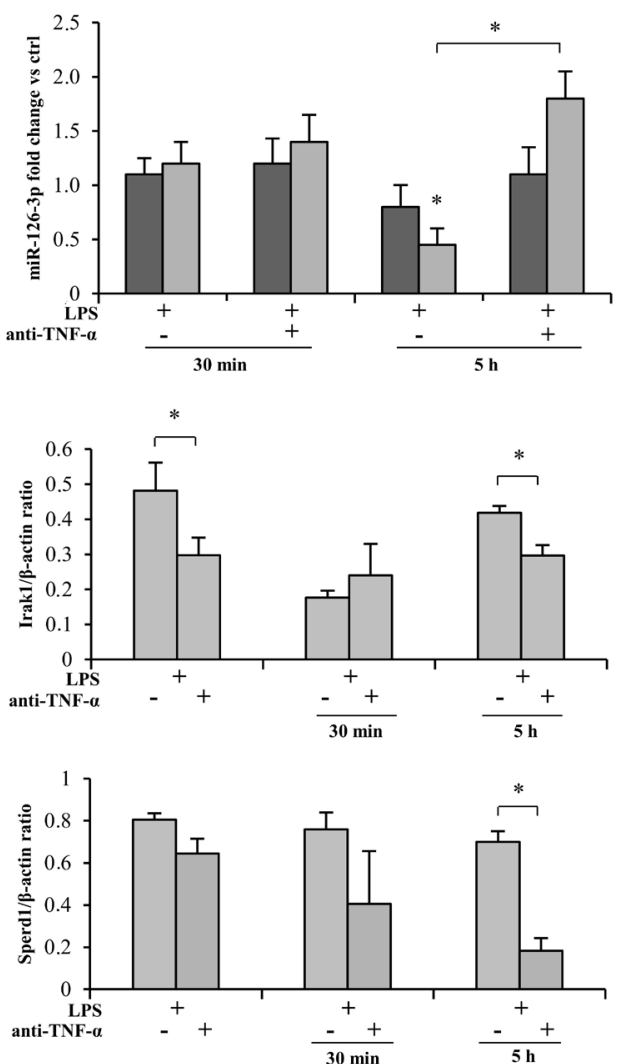
(A)

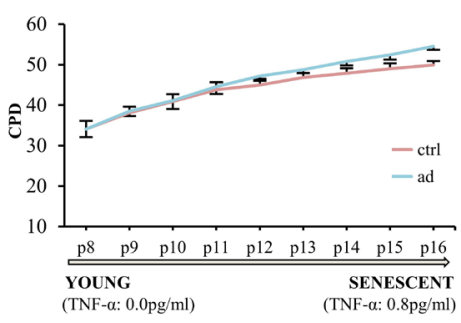

(D)

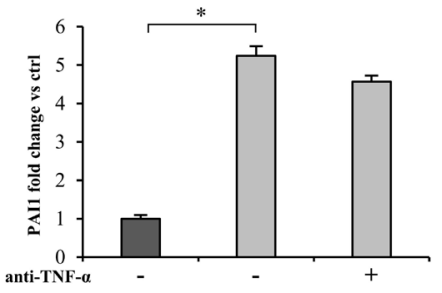

(G)

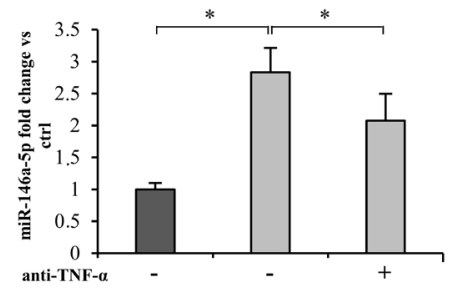

(I)
(B)

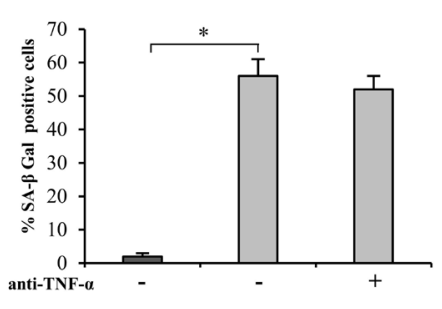

(E)

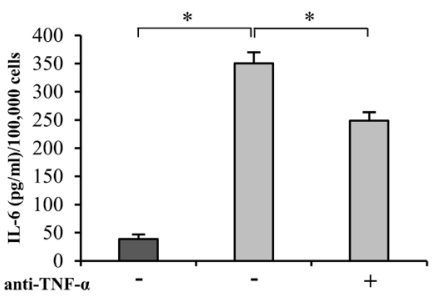

(C)

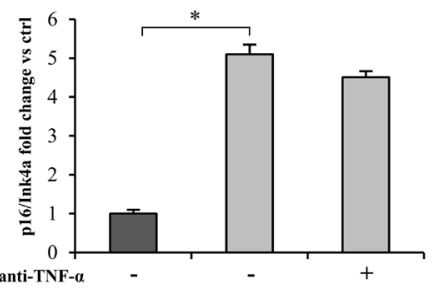

(F)

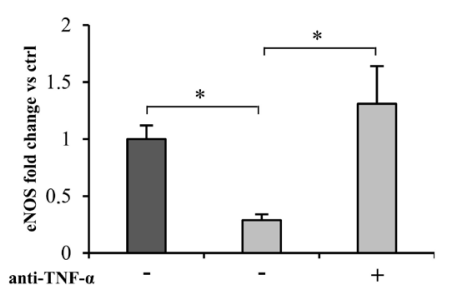

(H)

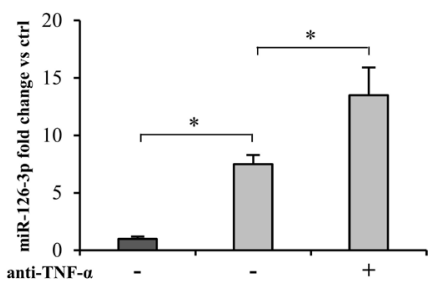

Young cells

Senescent cells
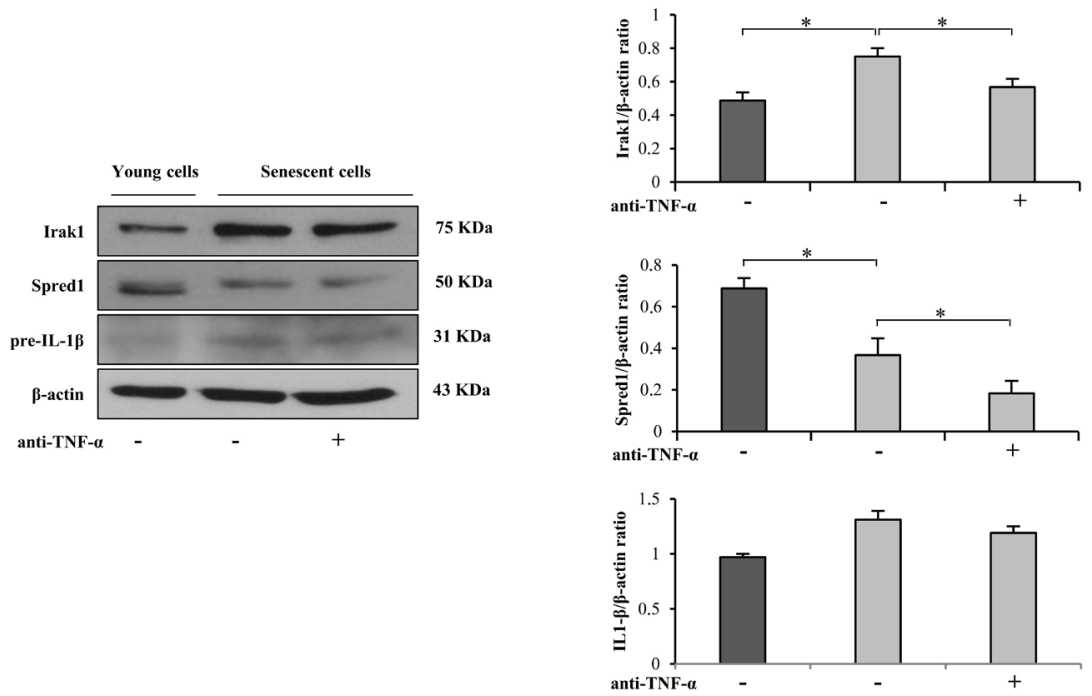

Figure 3: TNF- $\alpha$ blockade and HUVECs replicative senescence and SASP acquisition. A. Cumulative population doublings (CPDs) of HUVECs exposed to continuous anti-TNF- $\alpha$ treatment and of control cultures from 34 CPDs to complete growth arrest. Y axis, CPD; $x$ axis, number of passages. B. Percentage of SA- $\beta$-Gal-positive cells at the beginning of the curve (young cells) and at its end (senescent cells), with/without anti-TNF- $\alpha$ treatment. C. p16/Ink4a mRNA expression in young and senescent cells with/without antiTNF- $\alpha$ treatment. Data expressed as fold changes $v s$ young cells. D. PAI1 mRNA expression in young and senescent cells with/without anti-TNF- $\alpha$ treatment. Data expressed as fold changes $v s$ young cells. E. IL-6 release (pg/ml per 100,000 cells) into the culture medium by young and senescent cells with/without anti-TNF- $\alpha$ treatment. F. eNOS mRNA expression in young and senescent cells with/without anti-TNF- $\alpha$ treatment. Data expressed as fold changes $v s$ young cells. G. MiR-146a-5p expression in young and senescent cells with/ without anti-TNF- $\alpha$ treatment. Data expressed as fold changes $v s$ young cells. H. MiR-126-3p expression in young and senescent cells with/ without anti-TNF- $\alpha$ treatment. Data expressed as fold changes $v s$ young cells. I. Irak1, Spred1 and IL1 $\beta$ expression and densitometry data (normalized to $\beta$-actin) in young and senescent cells with/without anti-TNF- $\alpha$ treatment. * Student's $t$ test, $p<0.05$. Data are mean \pm S.D. of 3 independent experiments. 
$3 p$ expression (Figure 2E).

Neither Irak1 nor Spred1 were significant modulated in young cells (data not shown).

\section{- Modulation of interleukin IL-6}

The effect of adalimumab on IL-6 was investigated because it is the prototypical SASP protein $[3,4]$. Adalimumab treatment for $24 \mathrm{~h}$ induced a decreased IL- 6 release by young HUVECs (SA- $\beta-\mathrm{Gal}<5 \%$ ) exposed to LPS stimulation, attenuating the up-regulation due to LPS treatment; in contrast, no significant change was noted in senescent HUVECs (Supplementary Figure 2). Notably, IL-6 release was greater in LPS-untreated senescent HUVECs than in LPS-exposed young cells (Supplementary Figure 2).

\section{2) Effects of TNF- $\alpha$ inhibition on HUVECs undergoing replicative senescence}

Next, we tested whether continuous TNF- $\alpha$ blockade during replicative senescence reduces senescence/SASP markers in HUVECs. Since TNF- $\alpha$ was not detected in the culture medium of young cells (Figure 2A and Figure

(A)

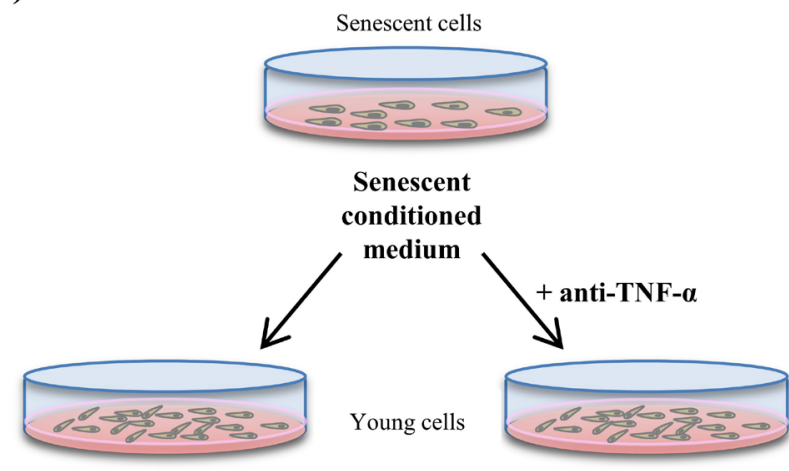

(C)

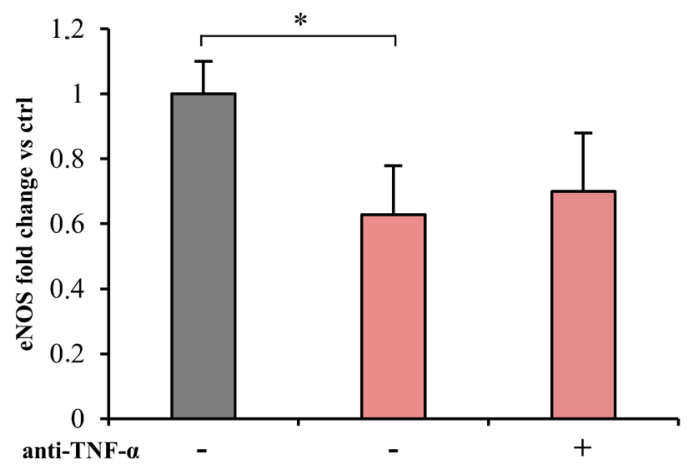

$3 \mathrm{~A}$ ), adalimumab was added beginning at $34 \mathrm{CPDs}$. The treatment failed to reduce the percentage of SA- $\beta-\mathrm{Gal}-$ positive cells (Figure 3A and B); in addition, it did not significantly affect the increase of p16/Ink4a and PAI1 expression, two classic markers of EC senescence (Figure $3 \mathrm{C}$ and $3 \mathrm{D})$.

Importantly, IL-6 released into the medium was significantly lower in adalimumab-treated cells at the end of the growth curve (Figure 3E), reflecting the reduction of SASP-related cytokines.

As regards eNOS, its down-regulation during replicative senescence was completely abolished by adalimumab (Figure 3F).

Adalimumab induced miR-146a-5p and Irak1 downregulation (Figure $3 \mathrm{G}$ and $3 \mathrm{I}$ ) as well as increased miR126-3p and decreased Spred1 expression (Figure 3H and 3I). Western blot analysis showed unchanged cellular IL$1 \beta$ protein levels in both young and senescent HUVECs (Figure 3I) and undetectable IL-1 $\beta$ levels in the culture medium (data not shown).

(B)

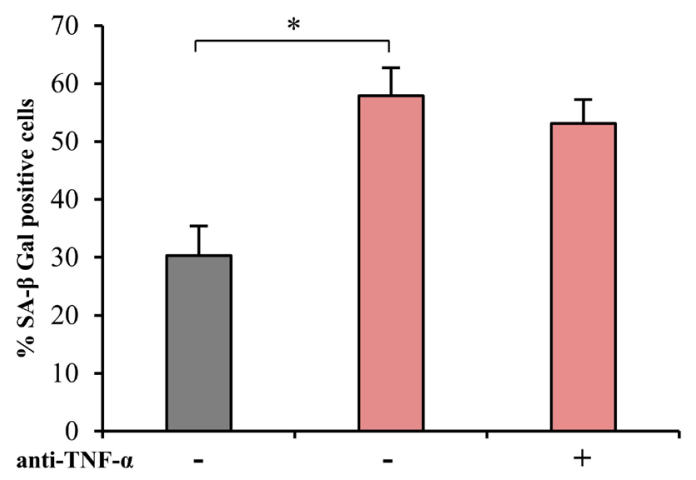

(D)

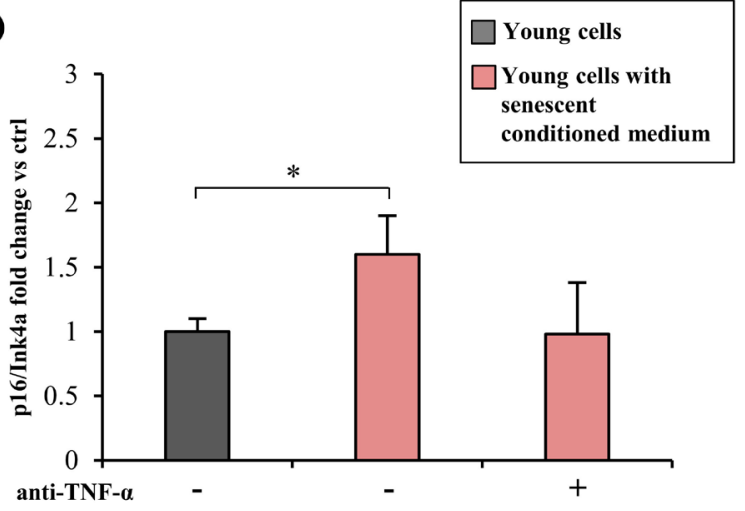

Figure 4: TNF- $\alpha$ blockade and bystander effect of HUVECs SASP. A. Drawing showing the experimental design. Conditioned medium from senescent cells (SA- $\beta$-Gal $>50 \%$ ) was mixed with $1 / 3$ of fresh medium (with $30 \%$ serum) and used to treat young cells (SA$\beta-\mathrm{Gal}<5 \%$ ) for 2 weeks, with/without anti-TNF- $\alpha$ treatment. Conditioned medium from young cells was used as control. B. Percentage of SA- $\beta$-Gal positive cells after 2 week exposure to conditioned media, with/without anti-TNF- $\alpha$ treatment. C. and D. eNOS and p16/Ink4a expression in cells treated with conditioned medium, with/without anti-TNF- $\alpha$ treatment. Data expressed as fold change $v s$ control cells. * Student's $t$ test, $p<0.05$. Data are mean \pm S.D. of 3 independent experiments. 


\section{Effects of TNF-a inhibition on the SASP bystander effect}

To test the ability of TNF- $\alpha$ inhibition to induce a bystander effect, young HUVECs were treated for 2 weeks with conditioned medium from senescent HUVECs (SA- $\beta$-Gal $>50 \%$ ) mixed with $1 / 3$ fresh medium (with $30 \%$ serum), with or without adalimumab (Figure 4A). Conditioned medium from young cells was used as control.
(A)

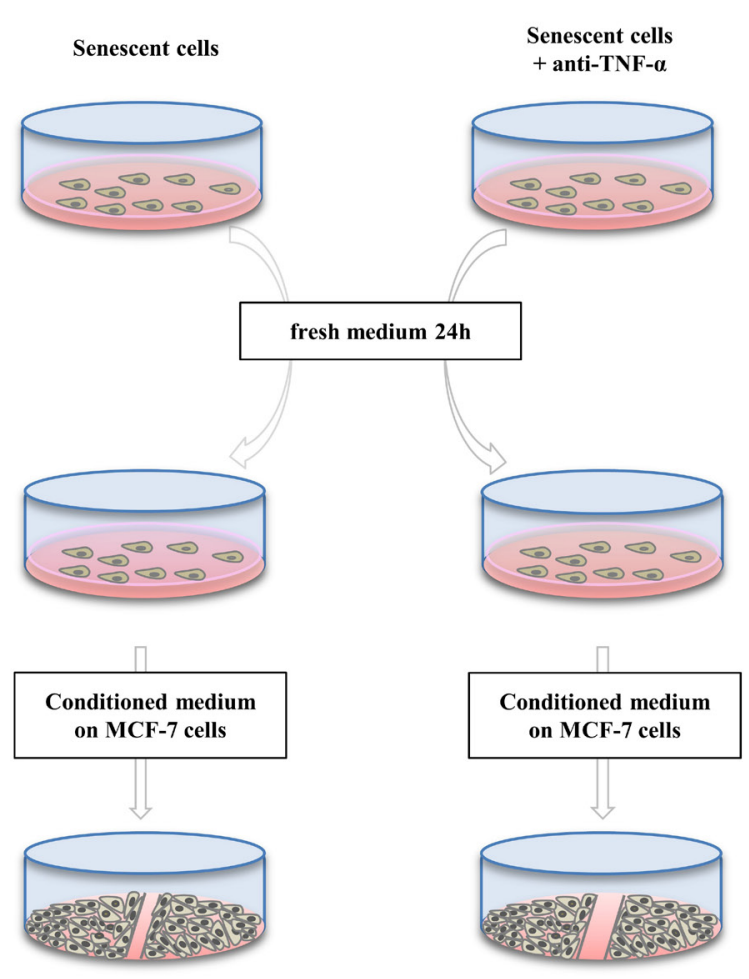

(D)

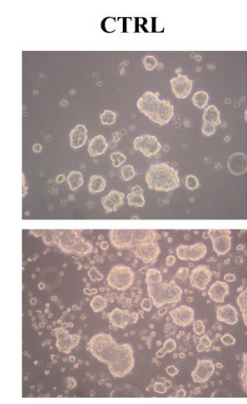

SEN-CM

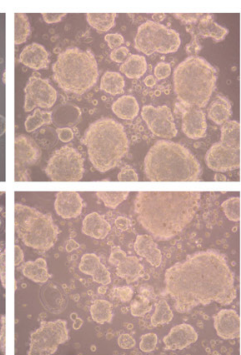

ATT SEN-CM

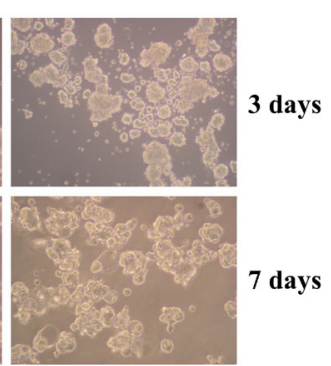

(B)

CTRL

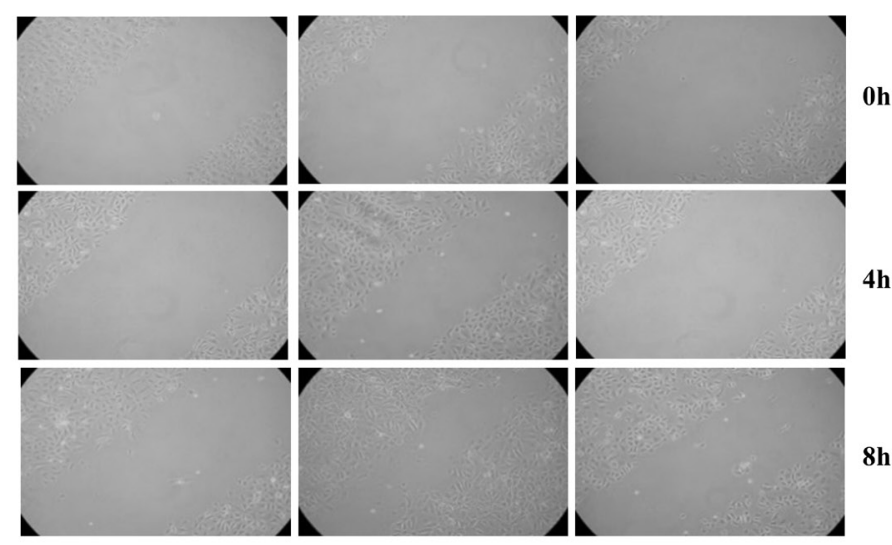

(C)

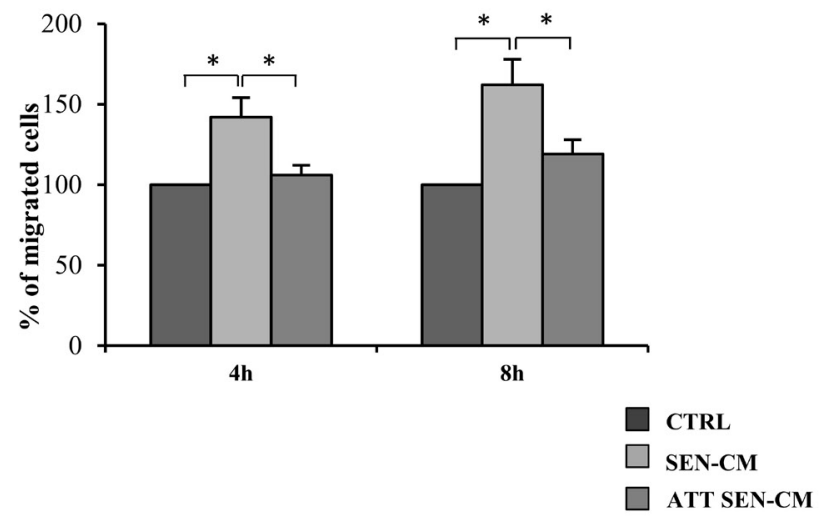

Figure 5: Anti-TNF- $\alpha$ treatment effect on pro-motility activity and mammosphers (MS) promotion of HUVECs secretome on MCF-7 tumor cell. A. Drawing showing the experimental design. Senescent cells exposed to anti-TNF- $\alpha$ long-term treatment and senescent control cells were switched to fresh medium for $24 \mathrm{~h}$ and then their conditioned medium was mixed with $1 / 3$ fresh DMEM. These mixtures, senescence conditioned medium (SEN-CM), and anti-TNF- $\alpha$ treated senescence conditioned medium (ATT SEN-CM) were used to treat MCF-7 in a wound healing assay. Conditioned medium from young cells was mixed with DMEM and used as control. B. Light microscopic photographs showing MCF-7 migration in the wound healing assay 0,4 and $8 \mathrm{~h}$ after treatment with SEN-CM or ATT SEN-CM. C. Percentage of migrating cells after 4 and $8 \mathrm{~h}$ exposure to SEN-CM and ATT SEN-CM. Data expressed as percent of control. D. Representative pictures of MCF7-derived mammosphers (MS) promotion induced by conditioned media obtained from young cells (CTRL-CM), senescent cells (SEN-CM), and anti-TNF- $\alpha$ treated senescent cells (ATT SEN-CM). E. Quantification of MCF7-derived mammospheres in presence of different conditioned media. Data are presented as number of MS per well, at 3 and 7 days. Data are mean \pm S.D. of 3 independent experiments. Scale bar $50 \mu \mathrm{m} .{ }^{*} p<0.05$. * Student's $t$ test, $p<0.05$. Data are mean \pm S.D. of 3 independent experiments. 
Exposure of young HUVECs to conditioned medium from senescent cells induced a doubling of SA$\beta$-Gal-positive cells, including adalimumab-treated ones (Figure 4B). The medium also induced eNOS downregulation and p16/Ink4a up-regulation; neither effect was significantly reversed by anti-TNF- $\alpha$ (Figure 4C and 4D).

\section{Effects of TNF- $\alpha$ inhibition in the secretome of senescent HUVECs on tumor cell migration}

Senescent cells exert a tumorigenic effect [3]. To test whether long-term anti-TNF- $\alpha$ treatment reduces the cell non-autonomous functions of the endothelial SASP, a wound healing assay was conducted using MCF-7 breast cancer cells and A549 lung cancer cells cultured in presence of conditioned medium from senescent HUVECs. Notably, the MCF-7 cell line is responsive to IL-6 [41, 42]. Senescent cells subjected to long-term adalimumab treatment and untreated were placed in fresh medium for $24 \mathrm{~h}$ and their conditioned medium was mixed with $1 / 3$ fresh DMEM. These mixtures, senescence conditioned medium (SEN-CM), and anti-TNF- $\alpha$ treated senescence conditioned medium (ATT SEN-CM) were used to treat MCF-7 cells in the wound healing assay (Figure 5A). Conditioned medium from young cells mixed with DMEM was used as control.

SEN-CM strongly promoted MCF-7 migration whereas ATT SEN-CM did not (Figure 5B and 5C), clearly indicating that long-term anti-TNF- $\alpha$ treatment reduces the HUVEC SASP. In contrast, migration of A549 cells was not enhanced by SEN-CM (data not shown), suggesting that different tumors respond differently to the SASP.

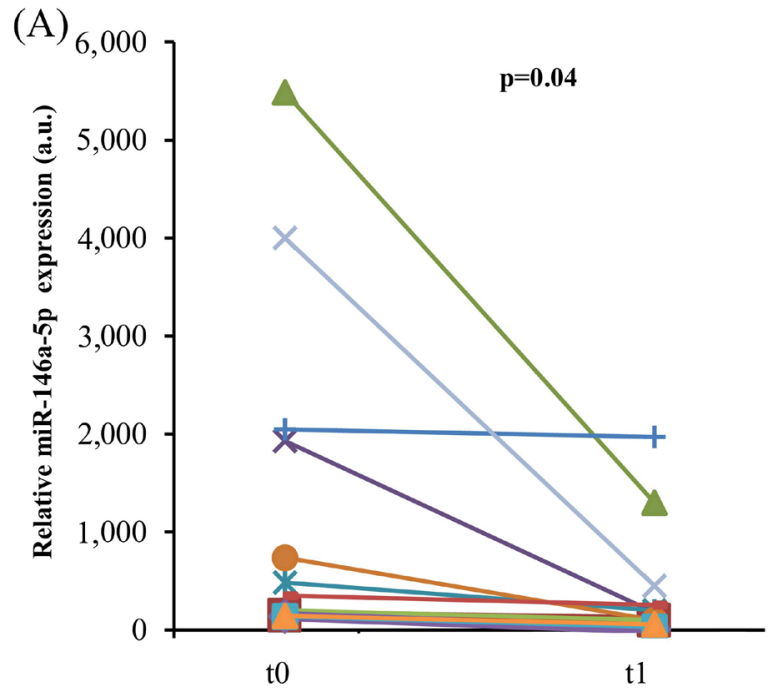

\section{Effects of TNF- $\alpha$ inhibition in the secretome of senescent HUVECs on mammospheres assay}

The mammosphere assay allows to propagate a population of putative cancer-stem-cells as floating spheroids [43-45]. This assays represents a useful surrogate test to screen the tumorigenic and metastatic potential of breast cancer cells [43].

The same conditioned media obtained from young cells (CTRL-CM), senescent cells (SEN-CM), and antiTNF- $\alpha$ treated senescent cells (ATT SEN-CM) used to treat MCF-7 cells in the wound healing assay were used for MCF-7 mammospheres (MS) assay (Figure 5D and 5E). Primary MS formation was assessed after 3 and 7 days .

SEN-CM strongly promoted the formation of MCF7-derived mammospheres, whereas in ATT SEN-CM this promotion is significantly reduced both at 3 and at 7 days $(p>0.05)$ (Figure 5D and 5E).

\section{Effects of TNF- $\alpha$ inhibition on CACs from psoriatic patients}

Psoriasis patients show elevated circulating levels of TNF- $\alpha$ compared with healthy subjects, and psoriasis has been associated with an increased incidence of ARDs [46, 47]. Given that CACs are monocytes capable of releasing pro-angiogenic cytokines, CACs from 10 psoriatic patients, receiving adalimumab after a wash-out period, were analyzed to establish whether anti-TNF- $\alpha$ monotherapy for 3 months is able to reduce miR-126-3p and miR-146a-5p expression. TNF- $\alpha$ inhibition affected miR-146a-5p levels (Figure 6A), as also noted in the experiments with THP-1 cells and HUVECs, suggesting

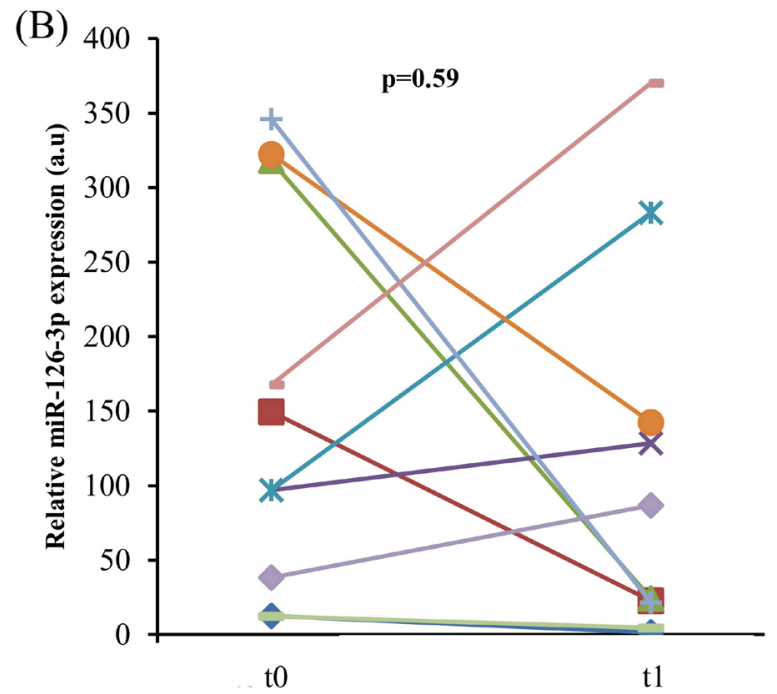

Figure 6: In vivo anti-TNF- $\alpha$ treatment and endothelial senescence-associated miR expression levels in psoriatic patients. MiR-146a-5p A. and miR-126-3p B. expression in CACs from 13 psoriasis patients before and after 3 month anti-TNF- $\alpha$ monotherapy with adalimumab. P from Student's $t$ test for paired samples. 
that the epigenetic modulation of inflammatory pathways induced by adalimumab in vitro resembles the modulation induced in vivo. Notably, miR-126-5p expression was not significantly affected in psoriasis patients, suggesting that the anti-inflammatory effects of adalimumab prevail on its proangiogenic effects (Figure 6B).

\section{DISCUSSION}

Selective removal of senescent cells and SASP attenuation are emerging as major goals of aging research. Avoiding the adverse effect associated with the SASP has a great potential to enhance successful aging [1]. Here we document that inhibition of TNF- $\alpha$ activity in ECs undergoing replicative senescence attenuated the SASP, as demonstrated by the down-regulation of IL-6, the suppression of miR-146a-5p and the increase of miR126-3p, respectively an inflamma-miR and an endo-miR, and their targets. Importantly, anti-TNF- $\alpha$ treatment also induced eNOS up-regulation, suggesting an enhanced endothelial function.

Interestingly, these significant effects induced in HUVECs undergoing replicative senescence were not associated with significant decrease of classic senescence biomarkers, such as SA- $\beta-$ Gal, p16/Ink4a, and PAI1.

Some studies have described the possibility of dissociating experimentally the SASP from senescence $[9,17]$. Although a number of reports have shown that SASP modulation influences the rate of senescence [9, $22,48]$, differences have been observed depending on the cytokines involved [17]. In our experimental model, i.e. HUVECs undergoing replicative senescence, the number of senescent cells was not significantly affected by continuous anti-TNF- $\alpha$ treatment, suggesting that TNF- $\alpha$ is not closely associated with the arrest of replicative growth. Although it has been demonstrated that IL-1 or TGF- $\beta$ blockade can attenuate SASP spread in different senescence models [9, 22], data on anti-TNF-a treatment were scarce and inconclusive [27, 28]. The present findings now indicate that anti-TNF- $\alpha$ treatment can restrain the SASP without significantly affecting senescence signal transmission, either autocrine or paracrine. Notably, our experimental model involved blocking the TNF- $\alpha$ spontaneously produced by ECs undergoing senescence, which never exceeds $1 \mathrm{pg} / \mathrm{ml}$ per 100,000 cells, whereas in other experimental models cells have been treated with greater (up to 10 fold) amounts of TNF- $\alpha$ [27]. Our data demonstrate that anti-TNF- $\alpha$ treatment in the physiological range can reduce some of the cell-non-autonomous effects of the SASP; in particular, conditioned medium from senescent cells treated with adalimumab reduced the migration rate of MCF-7 breast cancer cells and strongly attenuated the mammospheres promoting effect of the senescent HUVECs secretome, suggesting a decreased pro-tumorigenic and pro-metastatic behavior of the SASP under TNF- $\alpha$ blockade condition.
These findings lend support to the hypothesis that the SASP does not need to be completely suppressed to obtain significant effects, or to attenuate the onset/ progression of ARDs, including cancer [17].

TNF- $\alpha$ plays a large role in EC inflammation during aging [29]. Treatment with adalimumab reduces the levels of pro-inflammatory circulating cytokines and improves flow-mediated dilation [30, 31, 47], two well-established markers of endothelial aging [49]. Therefore, TNF- $\alpha$ modulation could have a key role both in aging rate and in ARD development and progression $[47,50]$.

Main limit of our study is that it refers only to the effect of TNF- $\alpha$ on SASP. A number of evidence suggest that several drugs, nutrition interventions and life-style modifications are able to modulate SASP, mainly through the activation of Toll-like receptors (TLRs) and NF- $\mathrm{KB}$ pathway activation [51]. SASP modulation should be more extensively investigated through other therapeutic strategies, such as agonist/antagonist of TLRs, focusing on the related decoy receptors and their miRNAs targets

In conclusion, anti-inflammatory treatments capable of restraining the SASP could contribute to delay ARD onset and progression, especially in patients with an established chronic inflammatory background $[1,8,52-$ 54]. Clearly, TNF- $\alpha$ inhibition has too many side effects to be administered as a clinical anti-aging treatment in old patients [27, 40, 47]. However, the present findings are in line with earlier reports $[9,17]$ that it is possible to dissociate the SASP from senescence, and encourage the search for substances, synthetic or natural, that not only suppress but also restrain the SASP.

Our data add a piece to the complex puzzle of inflammaging, furthering our knowledge of the mechanisms controlling the SASP in ECs [52] and the associated chronic inflammation that can promote the development and progression of the major ARDs $[8,54]$.

\section{EXPERIMENTAL PROCEDURES}

\section{Anti-TNF- $\alpha$ and LPS treatment}

After testing different pharmacologically appropriate adalimumab doses in BrDU and MTT assays (Supplementary Figure 1), $8 \mu \mathrm{g} / \mathrm{ml}$ of the human TNF- $\alpha$ inhibitor (Humira, Abbott, Lake Forest, IL, USA) was used in both short- and long-term experiments. This is the concentration commonly found in patient sera following injection of $0.8 \mathrm{ml}$ adalimumab at a concentration of 50 $\mathrm{mg} / \mathrm{ml}$ [40]. A random IgG at the same dose was always added to control cultures to avoid phenomena involving Fc receptor.

Lipopolysaccharide (LPS; Sigma-Aldrich, Taufkirchen, Germany) was added $(1 \mu \mathrm{g} / \mathrm{ml})$ to the medium as appropriate for the short-term experiments, 


\section{HUVEC and THP-1 culture}

HUVECs derived from 3 donor pools were purchased from Clonetics (Lonza, Basel, Switzerland) and cultured in EGM-2 endothelial growth medium (Lonza). Briefly, fresh cells were seeded at a density of $5000 / \mathrm{cm}^{2}$ in T 75 flasks (Corning Costar, Sigma Aldrich, St. Louis MO, USA); the medium was changed at $48 \mathrm{~h}$ intervals. Cultures reached confluence after 6-7 days, as assessed by light microscopic examination, and were passaged weekly. After trypsinization and before replating, harvested cells were counted using a hemocytometer. Replicative senescence was studied by culturing cells up to the $15 / 16^{\text {th }}$ passage. Cumulative population doubling (CPD) was calculated as the sum of all PD changes. Cells were divided into young (SA- $\beta-\mathrm{Gal}<5 \%$ ) and senescent $(\mathrm{SA}-\beta-\mathrm{Gal}>50 \%$ ).

SA- $\beta$-Gal activity was assessed as described previously [13].

Human monocytic THP-1 cells were purchased from ATCC (Rockville, MD, USA) and maintained in RPMI1640 medium supplemented with $10 \%$ heat-inactivated fetal bovine serum, $1 \%$ penicillin/streptomycin, and $1 \%$ L-glutamine (all from Euroclone, Milano, Italy).

\section{Protein extraction and immunoblotting}

Cells were washed twice in cold phosphate buffered saline (PBS). Total protein was extracted using RIPA buffer $(150 \mathrm{mMNaCl}, 10 \mathrm{mM}$ Tris, $\mathrm{pH}$ 7.2, $0.1 \%$ SDS, $1.0 \%$ Triton $\mathrm{X}-100,5 \mathrm{mM}$ EDTA, $\mathrm{pH} 8.0)$ containing a protease inhibitor cocktail (Roche Applied Science, Indianapolis, IN, USA). Protein concentration was determined using Bradford Reagent (Sigma-Aldrich, Milano, Italy). Total protein extracts $(40 \mu \mathrm{g})$ were separated by $10 \%$ SDS-PAGE and transferred to PVDF membranes (Bio-Rad, Hercules, CA, USA). Membranes were incubated overnight with primary anti-Spred 1 antibody diluted 1:1000 (Thermo Scientific, Pierce Biotechnology, Rockford, IL, USA), anti-Irak1 antibody diluted 1:250 (MBL International Corporation, Nagoya, Japan), and anti-IL-1 $\beta$ antibody diluted 1:1000 (Cell Signaling Technology, Beverly, MA, USA); subsequently they were incubated with a secondary antibody conjugated to horseradish peroxidase for $1 \mathrm{~h}$ at room temperature. Immunoreactive proteins were visualized using ECL Plus chemiluminescence substrate (GE Healthcare, Pittsburgh, PA, USA). Membranes were incubated with anti $\beta$-actin diluted 1:10,000 (Santa Cruz Biotechnology, Santa Cruz, CA, USA) as an endogenous control.
Total RNA enriched in miRNA species was purified from HUVECs using RNA purification kit according to the manufacturer's instructions (Norgen Biotek, Thorold, Canada).

\section{MiRNA quantification by RT q-PCR}

MiRNA expression was quantified using a modified real-time approach using the TaqMan miRNA RT kit and a miRNA assay (Applied Biosystems, Foster City, CA, USA). Briefly, total RNA was reverse-transcribed with a TaqMan MicroRNA RT kit. The $5 \mu \mathrm{l}$ R reaction volume contained $1 \mu \mathrm{l}$ of each miR-specific stem-loop primer, 1.7 $\mu l$ of input RNA, $0.4 \mu \mathrm{l}$ of $10 \mathrm{mM}$ dNTPs, $0.3 \mu \mathrm{l}$ reverse transcriptase, $0.5 \mu \mathrm{l} 10 \mathrm{x}$ buffer, $0.6 \mu \mathrm{l}$ RNAse inhibitor diluted 1:10, and $0.5 \mu 1 \mathrm{H}_{2} \mathrm{O}$. The mixture was incubated at $16{ }^{\circ} \mathrm{C}$ for $30 \mathrm{~min}$, at $42^{\circ} \mathrm{C}$ for $30 \mathrm{~min}$, and at $85^{\circ} \mathrm{C}$ for $5 \mathrm{~min}$. Quantitative real-time PCR was subsequently performed. The $5 \mu \mathrm{l}$ PCR reaction volume included 0.25 $\mu l$ 20x TaqMan MicroRNA Assay, which contained the PCR primers and probes (5'-FAM), $2.75 \mu \mathrm{l} 2 \mathrm{x}$ TaqMan Universal Master mix no UNG (Applied Biosystems), and $2.00 \mu \mathrm{RT}$ product. The reaction was first incubated at 95 ${ }^{\circ} \mathrm{C}$ for $2 \mathrm{~min}$, followed by 40 cycles of $95{ }^{\circ} \mathrm{C}$ for $15 \mathrm{sec}$ and $60{ }^{\circ} \mathrm{C}$ for $1 \mathrm{~min}$. Data were analyzed with Real Time PCR Opticon Monitor version 2 (MJ Research, Bio-Rad) with automatic $\mathrm{Ct}$ setting for adjusting the baseline and threshold for $\mathrm{Ct}$ determination.

MiR expression in HUVECs was evaluated using RNU44 as the reference; for miR expression in CACs, RNU $6 \mathrm{~b}$ was used as the reference. Each reaction was performed in duplicate.

\section{mRNA expression}

For mRNA gene expression, total RNA was reversetranscribed using $\mathrm{RT}^{2}$ First Strand Kit (Norgen Biotek) according to the manufacturer's instructions. The cDNA thus obtained was used for subsequent quantitative realtime PCR (qPCR). qPCR reactions were conducted on a MyiQ Single Color Real-Time PCR Detection System (Bio-Rad) in a $15 \mu$ total reaction volume using $\mathrm{iQ}^{\mathrm{TM}}$ SYBR Green Supermix (Bio-Rad). The mRNA expression of the genes of interest was calculated with reference to three reference genes, $\beta$-actin, $\beta 2 \mathrm{M}$, and HPRT1. Primer concentration was $300 \mathrm{nM}$ for $\beta$-actin and HPRT1 and $400 \mathrm{nM}$ for the other primers. Each reaction was run in duplicate and always included a no-template control. All primers have been described previously [55].

The qPCR reaction was programmed to start with a 3 min denaturation step at $95^{\circ} \mathrm{C}$ for polymerase activation followed by 40 cycles of $15 \mathrm{sec}$ denaturation at $95^{\circ} \mathrm{C}$ and 
$30 \mathrm{sec}$ of annealing/extension at $60{ }^{\circ} \mathrm{C}$, during which fluorescence was measured. Next, a melting curve was constructed by raising the temperature from $55^{\circ} \mathrm{C}$ to 95 ${ }^{\circ} \mathrm{C}$ in sequential $0.5^{\circ} \mathrm{C}$ steps for $6 \mathrm{sec}$. PCR efficiencies were all between $90 \%$ and $110 \%$ and were taken into account when calculating $\mathrm{Ct}$ values. mRNA quantification was assessed using the $2^{-\mathrm{DDCt}}$ method.

\section{Cell viability assay}

The (3-(4,5-dimethylthiazol-2-yl)-2,5diphenyltetrazolium bromide (MTT) assay was used to test cell viability. Cells were grown in 96-well plates at a density of $2 \times 103$ cells/well. After $18 \mathrm{~h}$ they were washed with fresh medium then treated with differential doses of adalimumab. After $24 \mathrm{~h}$ pretreatment, $100 \mu \mathrm{l}$ MTT (1 mg/ $\mathrm{ml}$ ) was added and incubated for $4 \mathrm{~h}$; the formazan salt that formed was solubilized by adding $200 \mu$ dimethyl sulfoxide and its amount was determined by measuring optical density at $540 \mathrm{~nm}$ using a microplate reader (MPT Reader, Invitrogen, Milano, Italy).

\section{Cytokine production}

Culture supernatants were collected at the end of each incubation, centrifuged, and stored at $-20{ }^{\circ} \mathrm{C}$ until use in the assays. IL- 6 and TNF- $\alpha$ concentrations were measured using a commercially available, high-sensitivity ELISA kit (Invitrogen) or a 4 custom cytokine multiplex (Tema Ricerca, Castenaso, Bologna).

\section{BrDU assay}

DNA Cell proliferation ELISA, BrdU (colorimetric) was purchased from Roche Diagnostics (Mannheim, Germany). Cells were plated in triplicate at a density of $5 \times 103 / \mathrm{cm}^{2}$ in $96-$ well plates and treated with various doses of adalimumab; BrdU labeling solution was then added and plates were read after $24 \mathrm{~h}$ incubation according to the manufacturer's instructions.

\section{Psoriasis patients}

A total of 10 psoriatic patients were enrolled in the study. The mean age was $53 \pm 14$ years, 8 males and 2 females. The study protocol was approved by the Ethics Committee of UNIVPM (Ancona, Italy) and all enrolled patients provided a written informed consent. All patients received 3 months of adalimumab monotherapy after a 12 weeks-wash-out period from previous therapy.

\section{CAC isolation and RNA extraction}

CACs were isolated from approximately 14 $\mathrm{ml}$ heparinized peripheral blood. Peripheral blood mononuclear cells (PBMCs) were isolated by densitygradient centrifugation with Ficoll (Ficoll-Paque ${ }^{\mathrm{TM}}$ PLUS, GE Healthcare Bio-Sciences Uppsala, Sweden) within 2 $\mathrm{h}$ of collection. Then 5x106 PBMCs were plated on 24well fibronectin-coated plates (BD Biosciences, Mountain View, CA, USA) and maintained in endothelial basal medium (EBM; Clonetics-Lonza, Walkersville, MD USA) supplemented with EGM SingleQuots and $20 \%$ fetal calf serum for 4 days. After 4 days in culture, non-adherent cells were removed by washing in PBS, whereas adherent cells were lysed directly in the culture wells.

The CAC phenotype was confirmed by cellular uptake of acetylated LDL (DiI-acLDL) and binding of FITC-conjugated lectin from Ulex europaeus (UEA-1) by fluorescence microscopy. Briefly, to detect DiLDL uptake, cells were incubated with DiLDL $(2.4 \mu \mathrm{g} / \mathrm{ml})$ (Molecular Probes, Eugene, OR, USA) at $37{ }^{\circ} \mathrm{C}$ for 2 h. To detect UEA-1 binding, cells were fixed with $2 \%$ paraformaldehyde for $15 \mathrm{~min}$ and incubated with FITClabeled UEA-1 (10 $\mu \mathrm{g} / \mathrm{ml})$ (UEA-1, Sigma, St. Louis, MO, USA) for $1 \mathrm{~h}$. Double-stained cells positive for both UEA1 and DiLDL were regarded as CACs. RNA was purified according to the instruction manual of the Total RNA Extraction kit (Norgen Biotek).

\section{Cultures and generation of MCF7 mammospheres (MS)}

MCF7 were grown in RPMI $1640+10 \%$ FBS medium. MCF7-derived mammospheres (MS) were obtained by plating 2500 cells into $3-\mathrm{cm}^{2}$ low-attachment wells (Corning, NY, USA) filled with mammary epithelial growth medium (MEGM), supplemented with MEGM bullet kit (Lonza Ltd, Basel, Switzerland). Primary MS formation was assessed after 3 and 7 days and photographed using a inverted microscope (Olympus CKX41, digital cameras Olympus C-5060, Japan). Only MS with an apparent diameter of $\geq 50 \mu \mathrm{m}$ were scored for statistical analysis, as previously described [43, 44].

\section{Statistical analysis}

Data are mean \pm standard deviation (S.D.) of at least three independent experiments. Student's $t$ test was applied to determine differences between samples. The $t$ test for paired samples was used to determine differences in miRNA expression in CACs before and after adalimumab treatment. $P$ values $<0.05$ were considered significant. 


\section{CONFLICTS OF INTEREST}

None of the authors have competing interests.

\section{Authors' contributions}

FP and AG performed THP1 and HUVECs experiments, including tumor cell lines wound healing assay. FB and LT characterized senescent HUVECs. RR and FM performed CAC purification and characterization. MB and SDC performed breast-cancer derived mammosphere assay. $\mathrm{KG}$ and $\mathrm{AC}$ recruited blood samples from psoriasis patients. FO was responsible for statistical analysis. FP and FO designed the study and drafted the manuscript. MRR, AO, AC and ADP revised the manuscript critically. All authors read and approved the final manuscript.

\section{REFERENCES}

1. Tchkonia T, Zhu Y, van Deursen J, Campisi J, Kirkland JL. Cellular senescence and the senescent secretory phenotype: therapeutic opportunities. J Clin Invest. 2013; 123: 966-72.

2. Franceschi C, Bonafè M, Valensin S, Olivieri F, De Luca M, Ottaviani E, De Benedictis G. Inflamm-aging: an evolutionary perspective on immunosenescence. Ann N Y Acad Sci. 2000; 908: 244-54.

3. Campisi J, d'Adda di Fagagna F. Cellular senescence: when bad things happen to good cells. Nat Rev Mol Cell Biol. 2007; 8: 729-40.

4. Freund A, Orjalo AV, Desprez PY, Campisi J. Inflammatory networks during cellular senescence: causes and consequences. Trends Mol Med. 2010; 16: 238-46.

5. Childs BG, Durik M, Baker DJ, van Deursen JM. Cellular senescence in aging and age-related disease: from mechanisms to therapy. Nat Med. 2015 Dec;21:1424-35.

6. Newgard CB, Sharpless NE. Coming of age: molecular drivers of aging and therapeutic opportunities. J Clin Invest. 2013 Mar;123(3):946-50. doi: 10.1172/JCI68833

7. Salminen A, Kauppinen A, Kaarniranta K. Emerging role of $\mathrm{NF}-\mathrm{\kappa B}$ signaling in the induction of senescence-associated secretory phenotype (SASP). Cell Signal. 2012; 24: 835-45.

8. Jurk D, Wilson C, Passos JF, Oakley F, Correia-Melo C, Greaves L, Saretzki G, Fox C, Lawless C, Anderson R, Hewitt G, Pender SL, Fullard N, et al. Chronic inflammation induces telomere dysfunction and accelerates ageing in mice. Nat Commun. 2014; 2: 4172.

9. Acosta JC, Banito A, Wuestefeld T, Georgilis A, Janich P, Morton JP, Athineos D, Kang TW, Lasitschka F, Andrulis M, Pascual G, Morris KJ, Khan S, et al. A complex secretory program orchestrated by the inflammasome controls paracrine senescence. Nat Cell Biol. 2013; 15: 978 90.

10. Zhang G, Li J, Purkayastha S, Tang Y, Zhang H, Yin Y, Li
B, Liu G, Cai D. Hypothalamic programming of systemic ageing involving IKK- $\beta$, NF- $\kappa$ B and GnRH. Nature. 2013; 497: 211-6.

11. Youm YH, Grant RW, McCabe LR, Albarado DC, Nguyen KY, Ravussin A, Pistell P, Newman S, Carter R, Laque A, Münzberg H, Rosen CJ, Ingram DK, et al. Canonical Nlrp3 inflammasome links systemic low-grade inflammation to functional decline in aging. Cell Metab. 2013; 18: 519-32.

12. Ferrand M, Kirsh O, Griveau A, Vindrieux D, Martin N, Defossez PA, Bernard D. Screening of a kinase library reveals novel pro-senescence kinases and their common NF-kB-dependent transcriptional program. Aging (Albany NY). 2015; 7: 986-1003.

13. Baker DJ, Wijshake $\mathrm{T}$, Tchkonia $\mathrm{T}$, LeBrasseur NK, Childs BG, van de Sluis B, Kirkland JL, van Deursen JM. Clearance of p16Ink4a-positive senescent cells delays ageing-associated disorders. Nature. 2011; 479: 232-6.

14. Waaijer ME, Parish WE, Strongitharm BH, van Heemst D, Slagboom PE, de Craen AJ, Sedivy JM, Westendorp RG, Gunn DA, Maier AB. The number of p16INK4a positive cells in human skin reflects biological age. Aging Cell. 2012; 11: 722-5.

15. Olivieri F, Lazzarini R, Babini L, Prattichizzo F, Rippo MR, Tiano L, Di Nuzzo S, Graciotti L, Festa R, Brugè F, Orlando P, Silvestri S, Capri M, et al. Anti-inflammatory effect of ubiquinol-10 on young and senescent endothelial cells via miR-146a modulation. Free Radic Biol Med. 2013; 63: 410-20.

16. Kozieł R, Ruckenstuhl C, Albertini E, Neuhaus M, Netzberger C, Bust M, Madeo F, Wiesner RJ, Jansen-Dürr P. Methionine restriction slows down senescence in human diploid fibroblasts. Aging Cell. 2014; 13: 1038-48.

17. Laberge RM, Zhou L, Sarantos MR, Rodier F, Freund A, de Keizer PL, Liu S, Demaria M, Cong YS, Kapahi P, Desprez PY, Hughes RE, Campisi J. Glucocorticoids suppress selected components of the senescence-associated secretory phenotype. Aging Cell. 2012; 11: 569-78.

18. Freund A, Patil CK, Campisi J. p38MAPK is a novel DNA damage response-independent regulator of the senescenceassociated secretory phenotype. EMBO J. 2011; 30: 153648.

19. Wu Z, Yu Y, Liu C, Xiong Y, Montani JP, Yang Z, Ming XF. Role of p38 mitogen-activated protein kinase in vascular endothelial aging: interaction with Arginase-II and S6K1 signaling pathway. Aging (Albany NY). 2015; 7 : 7081.

20. Lim H, Park H, Kim HP. Effects of flavonoids on senescence-associated secretory phenotype formation from bleomycin-induced senescence in BJ fibroblasts. Biochem Pharmacol. 2015; pii: S0006-2952 00329-9.

21. Zhu Y, Tchkonia T, Pirtskhalava T, Gower AC, Ding H, Giorgadze N, Palmer AK, Ikeno Y, Hubbard GB, Lenburg M, O'Hara SP, LaRusso NF, Miller JD, et al. The Achilles' heel of senescent cells: from transcriptome to senolytic 
drugs. Aging Cell. 2015; 14: 644-58.

22. Hubackova S, Krejcikova K, Bartek J, Hodny Z. IL1and TGF $\beta$-Nox4 signaling, oxidative stress and DNA damage response are shared features of replicative, oncogene-induced, and drug-induced paracrine 'bystander senescence'. Aging (Albany NY). 2012; 4: 932-51.

23. Nelson DM, McBryan T, Jeyapalan JC, Sedivy JM, Adams PD. A comparison of oncogene-induced senescence and replicative senescence: implications for tumor suppression and aging. Age (Dordr). 2014; 36: 9637.

24. Purcell M, Kruger A, Tainsky MA. Gene expression profiling of replicative and induced senescence. Cell Cycle. 2014; 13, 3927-37.

25. Donato AJ, Black AD, Jablonski KL, Gano LB, Seals DR. Aging is associated with greater nuclear NF kappa $\mathrm{B}$, reduced I kappa B- $\alpha$, and increased expression of proinflammatory cytokines in vascular endothelial cells of healthy humans. Aging Cell. 2008; 7: 805-12.

26. Kuilman T, Michaloglou C, Vredeveld LC, Douma S, van Doorn R, Desmet CJ, Aarden LA, Mooi WJ, Peeper DS. Oncogene-induced senescence relayed by an interleukindependent inflammatory network. Cell. 2008; 133: 1019-31.

27. Zhang Y, Herbert BS, Rajashekhar G, Ingram DA, Yoder MC, Clauss M, Rehman J. Premature senescence of highly proliferative endothelial progenitor cells is induced by tumor necrosis factor-alpha via the p38 mitogen-activated protein kinase pathway. FASEB J. 2009; 23: 1358-65.

28. Carracedo J, Buendía P, Merino A, Madueño JA, Peralbo E, Ortiz A, Martín-Malo A, Aljama P, Rodríguez M, Ramírez R. Klotho modulates the stress response in human senescent endothelial cells. Mech Ageing Dev. 2012; 133: 647-54.

29. Zhang H, Park Y, Wu J, Chen Xp, Lee S, Yang J, Dellsperger KC, Zhang C. Role of TNF-alpha in vascular dysfunction. Clin Sci (Lond). 2009; 116: 219-30.

30. Brezinski EA, Follansbee MR, Armstrong EJ, Armstrong AW. Endothelial dysfunction and the effects of TNF inhibitors on the endothelium in psoriasis and psoriatic arthritis: a systematic review. Curr Pharm Des. 2014; 20: 513-28.

31. Avgerinou G, Tousoulis D, Siasos G, Oikonomou E, Maniatis K, Papageorgiou N, Paraskevopoulos T, Miliou A, Koumaki D, Latsios G, Therianiou A, Trikas A, Kampoli $\mathrm{AM}$, et al. Anti-tumor necrosis factor $\alpha$ treatment with adalimumab improves significantly endothelial function and decreases inflammatory process in patients with chronic psoriasis. Int J Cardiol. 2011; 151: 382-3.

32. Campanati A, Moroncini G, Ganzetti G, Pozniak KN, Goteri G, Giuliano A, Martina E, Liberati G, Ricotti F, Gabrielli A, Offidani A. adalimumab modulates angiogenesis in psoriatic skin eur j inflam. 2013;11:489-498

33. De Simone C, Amerio P, Amoruso G, Bardazzi F, Campanati A, Conti A, Gisondi P, Gualdi G, Guarneri C, Leoni L, Loconsole F, Mazzotta A, Musumeci ML, Piaserico S, Potenza C, Prestinari F. Immunogenicity of
anti-TNF $\alpha$ therapy in psoriasis: a clinical issue? Expert Opin Biol Ther. 2013;13:1673-82.

34. Campanati A, Goteri G, Simonetti O, Ganzetti G, Giuliodori K, Giuliano A, Sabato S, Stramazzotti D, Gulini E, Dusi D, De Blasio S, Fabris G, Offidani A. Angiogenesis in psoriatic skin and its modifications after administration of etanercept: videocapillaroscopic, histological and immunohistochemical evaluation. Int $\mathrm{J}$ Immunopathol Pharmacol. 2009;22:371-7.

35. Inui M, Martello G, Piccolo S. MicroRNA control of signal transduction. Nat Rev Mol Cell Biol. 2010; 11: 252-63.

36. Dimri GP, Lee X, Basile G, Acosta M, Scott G, Roskelley C, Medrano EE, Linskens M, Rubelj I, Pereira-Smith O, Peacocke M, Campisi J. A biomarker that identifies senescent human cells in culture and in aging skin in vivo. Proc Natl Acad Sci U S A. 1995; 92: 9363-7.

37. Veitonmäki N, Fuxe J, Hultdin M, Roos G, Pettersson RF, Cao Y. Immortalization of bovine capillary endothelial cells by hTERT alone involves inactivation of endogenous p16INK4A/pRb. FASEB J. 2003; 17: 764-6.

38. Kortlever RM, Higgins PJ, Bernards R. Plasminogen activator inhibitor-1 is a critical downstream target of p53 in the induction of replicative senescence. Nat Cell Biol. 2006; 8: 877-84.

39. Matsushita H, Chang E, Glassford AJ, Cooke JP, Chiu CP, Tsao PS. eNOS activity is reduced in senescent human endothelial cells: Preservation by hTERT immortalization. Circ Res. 2001; 89: 793-8.

40. den Broeder A, van de Putte L, Rau R, Schattenkirchner M, Van Riel P, Sander O, Binder C, Fenner H, Bankmann Y, Velagapudi R, Kempeni J, Kupper H. A single dose, placebo controlled study of the fully human anti-tumor necrosis factor-alpha antibody adalimumab (D2E7) in patients with rheumatoid arthritis. J Rheumatol. 2002; 29: 2288-98.

41. Oglesby IK, Bray IM, Chotirmall SH, Stallings RL, O’Neill SJ, McElvaney NG, Greene CM. miR-126 is downregulated in cystic fibrosis airway epithelial cells and regulates TOM1 expression. J Immunol. 2010; 184: 1702-9.

42. Zacarias-Fluck MF, Morancho B, Vicario R, Luque Garcia A, Escorihuela M, Villanueva J, Rubio IT, Arribas J. Effect of cellular senescence on the growth of HER2-positive breast cancers. J Natl Cancer Inst. 2015; 107pii: djv020.

43. Sansone P, Storci G, Tavolari S, Guarnieri T, Giovannini C, Taffurelli M, Ceccarelli C, Santini D, Paterini P, Marcu KB, Chieco P, Bonafè M. IL-6 triggers malignant features in mammospheres from human ductal breast carcinoma and normal mammary gland. J Clin Invest. 2015; 117: 39884002.

44. Papi A, Storci G, Guarnieri T, De Carolis S, Bertoni S, Avenia N, Sanguinetti A, Sidoni A, Santini D, Ceccarelli C, Taffurelli M, Orlandi M, Bonafé M. Peroxisome proliferator activated receptor- $\alpha /$ hypoxia inducible factor- $1 \alpha$ interplay sustains carbonic anhydrase IX and 
apoliprotein E expression in breast cancer stem cells. PLoS One. 2013;8:e54968.

45. Papi A, De Carolis S, Bertoni S, Storci G, Sceberras V, Santini D, Ceccarelli C, Taffurelli M, Orlandi M, Bonafé M. PPAR $\gamma$ and RXR ligands disrupt the inflammatory cross-talk in the hypoxic breast cancer stem cells niche. J Cell Physiol. 2014;229:1595-606.

46. Henseler T, Christophers E. Disease concomitance in psoriasis. J Am Acad Dermatol. 1995; 32: 982-6.

47. Hugh J, Van Voorhees AS, Nijhawan RI, Bagel J, Lebwohl M, Blauvelt A, Hsu S, Weinberg JM. From the Medical Board of the National Psoriasis Foundation: The risk of cardiovascular disease in individuals with psoriasis and the potential impact of current therapies. J Am Acad Dermatol. 2014; 70: 168-77.

48. McCarthy DA, Clark RR, Bartling TR, Trebak M, Melendez JA. Redox control of the senescence regulator interleukin$1 \alpha$ and the secretory phenotype. J Biol Chem. 2013; 288: 32149-59.

49. Maggio M, Guralnik JM, Longo DL, Ferrucci L. Interleukin-6 in aging and chronic disease: a magnificent pathway. J Gerontol A Biol Sci Med Sci. 2006; 61: 575-84.

50. Steyers CM 3rd, Miller FJ Jr. Endothelial dysfunction in chronic inflammatory diseases. Int J Mol Sci. 2014; 15: 11324-49.

51. Balistreri CR, Candore G, Accardi G, Colonna-Romano

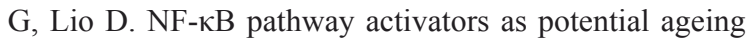
biomarkers: targets for new therapeutic strategies. Immun Ageing. 2013;10:24.

52. Stepanova M, Rodriguez E, Birerdinc A, Baranova A (2015) Age-independent rise of inflammatory scores may contribute to accelerated aging in multimorbidity. Oncotarget. 2015; 6: 1414-21. doi: 10.18632/ oncotarget. 2725 .

53. Longo VD, Antebi A, Bartke A, Barzilai N, Brown-Borg HM, Caruso C, Curiel TJ, de Cabo R, Franceschi C, Gems D, Ingram DK, Johnson TE, Kennedy BK, et al. Interventions to slow aging in humans: are we ready? Aging Cell. 2015; 14: 497-510.

54. Prattichizzo F, Bonafe M, Ceka A, Giuliani A, Rippo MR, Re M, Antonicelli R, Procopio AD, Olivieri F. Endothelial cell senescence and inflammaging: microRNAs as biomarkers and innovative therapeutic tools. Curr Drug Targets. 2015; [Epub ahead of print].

55. Olivieri F, Bonafè M, Spazzafumo L, Gobbi M, Prattichizzo F, Recchioni R, Marcheselli F, La Sala L, Galeazzi R, Rippo MR, Fulgenzi G, Angelini S, Lazzarini R, et al. Ageand glycemia-related miR-126-3p levels in plasma and endothelial cells. Aging (Albany NY). 2014; 6: 771-87. 